Polynomial Spatial Constraint Databases

Peer-reviewed author version

KUIJPERS, Bart (2015) Polynomial Spatial Constraint Databases. In: Shekhar, Shashi; Xiong, Hui (Ed.). Encyclopedia of GIS, p. 879-880.

Handle: http://hdl.handle.net/1942/18539 


\title{
Polynomial Spatial Constraint Databases
}

\author{
Bart Kuijpers \\ Databases and Theoretical Computer Science Research Group \\ Hasselt University and Transnational University of Limburg \\ bart.kuijpers@uhasselt.be
}

\section{SYNONYMS}

Constraint Database Systems; Constraint Query Languages; Infinite Relational Databases; Linear Constraint Databases; Moving Object Constraint Databases; Spatiotemporal Constraint Databases

\section{DEFINITION}

The framework of constraint databases provides a general model for spatial databases [4]. In the constraint model, a polynomial spatial constraint database contains a finite number of relations, that, although conceptually viewed as possibly infinite sets of points in some real space $\mathbf{R}^{n}$, are represented as a finite union of systems of polynomial equations and inequalities.

\section{MAIN TEXT}

More specifically, in a polynomial spatial constraint database, a relation is defined as a boolean combination (union, intersection, complement) of subsets of some real space $\mathbf{R}^{n}$ (in applications, typically $n=2$ or 3 ) that are definable by polynomial constraints of the form $p\left(x_{1}, \ldots, x_{n}\right) \geq 0$, where $p$ is a polynomial in the real variables $x_{1}, \ldots, x_{n}$ with integer coefficients. For example, the spatial relation consisting of the set of points on the upper half of the unit disk in $\mathbf{R}^{2}$ can be represented by the formula $x^{2}+y^{2} \leq 1 \wedge y \geq 0$. In practice, spatial relations will occur extended with thematic alpha-numeric information, like a name. In mathematical terminology, these spatial relations are known as semi-algebraic sets and their properties have been studied extensively [1].

The polynomial constraint database model was introduced by Kanellakis, Kuper, and Revesz [2] in 1990. The application of this model to spatial databases was described by Paredaens, Van den Bussche, Van Gucht [4]. This model was studied extensively in the 1990s and a state of the art book "Constraint databases," edited by G. Kuper, L. Libkin, J. Paredaens appeared in 2000 [3]. and the textbook "Introduction to Constraint Databases" by P. Revesz was published in 2002 [5].

\section{RECOMMENDED READING}

[1] J. Bochnak, M. Coste, and M.-F. Roy. Géométrie algébrique réelle. Springer-Verlag, 1987.

[2] P. C. Kanellakis, G. Kuper, and P. Z. Revesz. Constraint query languages. Journal of Computer and System Sciences, 51:26-52, 1995.

[3] G. M. Kuper, L. Libkin, and J. Paredaens, editors. Constraint Databases. Springer-Verlag, 2000.

[4] J. Paredaens, J. Van den Bussche, and D. Van Gucht. Towards a theory of spatial database queries. In Proceedings of the 13th ACM Symposium on Principles of Database Systems, pages 279-288, 1994.

[5] R. Z. Revesz. Introduction to Constraint Databases. Springer-Verlag, 2002. 